\title{
BMJ Open Caregivers' estimate of early childhood developmental status in rural Uganda: a cross-sectional study
}

\author{
Emmanuel Bonney (D) , ,2,3 Michele Villalobos, ${ }^{4}$ Jed Elison, ${ }^{1,3}$ Sooyeon Sung, ${ }^{1,3}$ \\ Adaeze Wosu, ${ }^{5}$ Charles SSemugabo, ${ }^{6}$ George Pariyo, ${ }^{7}$ Dan Kajungu, ${ }^{8}$ \\ Elizeus Rutebemberwa (D) , ${ }^{9,10}$ Adnan A Hyder, ${ }^{11}$ Dustin Gibson ${ }^{7}$
}

To cite: Bonney E, Villalobos M, Elison J, et al. Caregivers' estimate of early childhood developmental status in rural Uganda: a crosssectional study. BMJ Open 2021;11:e044708. doi:10.1136/ bmjopen-2020-044708

- Prepublication history and additional supplemental material for this paper are available online. To view these files, please visit the journal online (http://dx.doi.org/10.1136/ bmjopen-2020-044708).

Received 12 September 2020 Accepted 02 June 2021

Check for updates

(C) Author(s) (or their employer(s)) 2021. Re-use permitted under CC BY-NC. No commercial re-use. See rights and permissions. Published by BMJ.

For numbered affiliations see end of article.

Correspondence to Dr Emmanuel Bonney; ebonney10@gmail.com

\section{ABSTRACT}

Objective To characterise developmental milestones among young children living in rural communities in Uganda.

Design Cross-sectional study.

Setting Iganga-Mayuge Health and Demographic Surveillance Site in rural eastern Uganda.

Participants A total of 720 caregivers of children aged 3-4 years old from a health and demographic surveillance site in rural eastern Uganda were recruited into this study. Caregivers reported on their child's developmental skills and behaviours using the 10-item Early Childhood Development Index (ECDI) developed by UNICEF. Childhood development was characterised based on the ECDI's four domains: literacy-numeracy, learning/cognition, physical and socioemotional development. As an exploratory analysis, we implemented a hierarchical agglomerative cluster analysis to identify homogenous subgroups of children based on the features assessed. The cluster analysis was performed to identify potential subgroups of children who may be at risk of developmental problems. Results Between November 2017 and June 2018, 720 caregivers of children aged 3-4 years completed the ECDI. The proportions of children at risk of delay in each domain were as follows: literacy-numeracy: $75 \%(n=538)$; socioemotional development: $22 \%(n=157)$; physical: $3 \%$ $(n=22)$; and cognitive: $4 \%(n=32)$. The cluster analysis revealed a three-cluster solution that included $93 \%$ of children assigned to a low-risk group, $4 \%$ assigned to a moderate-risk group and $3 \%$ assigned to a high-risk group characterised by low scores in almost all domains.

Conclusion The findings suggest that a high proportion of children in rural eastern Uganda demonstrate poor literacy-numeracy skills. These results underscore the need to improve population-based screening and intervention efforts to improve early childhood developmental outcomes, particularly in literacy and socioemotional domains, in low-income and middleincome countries such as Uganda.

\section{INTRODUCTION}

Early childhood is a period of life where children acquire foundational skills necessary for healthy development, education, social wellbeing and economic productivity across the lifespan. ${ }^{12}$ Although the importance of early
Strengths and limitations of this study

- Outside of the Uganda Demographic and Health Surveys, this is the first study to document estimates of the number of children facing developmental challenges in rural Uganda using the UNICEF 10-item Early Childhood Development Index (ECDI).

- The study involved a relatively large populationrepresentative sample of caregivers recruited from rural communities in eastern Uganda.

- The study could not include a nationally representative sample as was done in the Uganda Demographic and Health Surveys due to logistical constraints.

- Another limitation of this work is that the ECDI was designed for a wide age range (36-59 months), and given the dynamic nature of development this wide age bracket makes it difficult to determine whether high ECDI scores reflect one's developmental skills or normal growth and maturation.

childhood development (ECD) in human capital development is well documented, current estimates show that more than 249 million children (43\%) younger than 5 years of age in low-income and middle-income countries (LMICs) may not reach their developmental potential due to extreme poverty, adversity and stunting. ${ }^{3-5}$ Without effective interventions, this loss of potential will negatively impact families and societies.

To be able to identify and implement costeffective programme to optimise ECD in these settings, population-based estimates of the number of children who are not developing appropriately are needed. Although previous studies have provided estimates of ECD status in different parts of the world, ${ }^{6-10}$ there is still limited data on ECD for young children in low-resource countries such as Uganda, especially those living in rural areas. Further, the majority of child development studies tend to characterise children's developmental abilities based on mean values. ${ }^{78}$ Although this approach has increased our knowledge 
about child development, using mean endpoints alone may potentially mask critical developmental insights that could inform the design of strategic interventions. It is therefore important to identify subgroups of children with atypical development who may be in need of tailored interventions. Characterising children's developmental status in low-resource settings using population-based measures provides an important opportunity to support contextually relevant ECD interventions at several levels of governance (ie, district, regional and national).

Global interest in ECD has contributed to the inclusion of the topic in several international agendas, including the United Nations Sustainable Development Goals (SDGs). ${ }^{411-14}$ The SDG target 4.2 states: 'by 2030, ensure that all girls and boys have access to quality early childhood development, care and pre-primary education so that they are ready for primary education'. ${ }^{11} 12$ Monitoring progress and achieving these goals require populationlevel ECD data for early identification of children at risk of developmental delay, to provide insights for prioritising interventions, and to justify the need for more financial and political investments in ECD, especially in low-resource settings. However, such data are currently limited in many low-income countries.

The Multiple Indicator Cluster Survey (MICS) programme is a UNICEF-supported household survey programme that aims to provide statistics on the situation of women and children. ${ }^{15} 16$ Since the first round in the mid-1990s, MICS has been conducted in over 100 countries. In some countries, MICS has been implemented in several rounds, thus allowing assessment of trends. Beginning in 2009, MICS included a short Early Childhood Development Index (ECDI) to measure the development of children aged 3 and 4 years old. ${ }^{15}$ Synthesis of ECDI data from the MICS suggests that $14.6 \%$ of children were at risk of delay in the cognitive domain, $26.2 \%$ were at risk of delay in the socioemotional domain and 36.8\% performed poorly in either or both domains. ${ }^{6}$ Children living in rural areas are reported to be facing greater difficulties in these domains than peers in urban or more affluent communities. ${ }^{6}{ }^{12}$

Uganda is an East African nation with a population of about 40 million people. Majority of the population $(57 \%)$ are believed to be children and youth. ${ }^{17}$ Like many African countries, there are substantial health disparities in Uganda even though the country has made progress in reducing maternal and child mortality. ${ }^{18}$ To build on the gains made in maternal and child health, the government of Uganda recently developed the national integrated ECD policy action plan ${ }^{19}$ to demonstrate its commitment to ensuring that all children in the country achieve their full potential. While these efforts are commendable, research on ECD is still low and the number of children in rural communities with poor developmental skills is yet to be elucidated. It is widely acknowledged that environmental influences and cultural practices impact child development especially in the areas of motor, cognitive and social development. ${ }^{237-9}$ In low-income contexts such as Uganda, negative environmental influences such as poverty, violence, unstable relationships, stress and exposure to toxins are common. ${ }^{236}$ Hence, population-based estimates on child development from different parts of the country are needed to inform resource allocation and direct investments in ECD to address identified needs.

Parent reports such as the ECDI are suitable for quantifying population-level estimates of ECD in low-income settings. The ECDI is a short (ie, 10 yes/no questions) caregiver-reported measure designed for children aged 3 and 4 years old and can easily be administered across diverse cultures. ${ }^{6}{ }^{12}$ The development of the ECDI has been previously described. ${ }^{15}$ The ECDI covers four domains (cognitive/learning, socioemotional, literacynumeracy and physical) and has been used in a number of countries within Sub-Saharan Africa. ${ }^{6}{ }^{11}$ Although it is acknowledged that the ECDI is limited in terms of scope, depth and psychometric evidence and has not been formally validated within Uganda, it was chosen for this study because it has been adopted as an interim population-level measure for reporting on the SDG 4, target 4.2.1. ${ }^{11}$ In addition, poor performance on the index has been shown to be associated with other known risk factors for adverse early development, such as lack of cognitive stimulation, poverty and stunting, thus lending support to utility of the index. ${ }^{6}$

While there is considerable interest in measuring ECD in Ugandan children, patterns of strengths and setbacks in developmental milestones have not been extensively documented. The overall aim of this paper was to describe the distribution of ECD competencies among rural Ugandan children using data derived from a populationrepresentative survey which included UNICEF's 10-item ECDI questionnaire. To achieve this aim, four specific objectives were formulated: first, to describe the demographic and sample characteristics of parents or caregivers and children in a rural Ugandan community; second, to determine estimates of the number of children with low developmental status based on caregiver assessments; third, to examine the association between caregiver (eg, educational level) and child (eg, gender) characteristics and children's developmental abilities; and lastly, to quantify putative profiles of risk among a sample of children aged 3 and 4 years old. Findings could inform the development of ECD curriculum that is locally responsive to the needs of children and families within the Ugandan setting.

\section{METHODS}

\section{Study design, setting and population}

This was a descriptive cross-sectional study conducted within the Iganga-Mayuge Health and Demographic Surveillance Site (IM-HDSS) in rural eastern Uganda. The IM-HDSS is a prospective population cohort set in a rural area in the Iganga and Mayuge districts, which are about $120 \mathrm{~km}$ from Uganda's capital, Kampala. ${ }^{20}$ The IM-HDSS has a population of about 90000 people in 65 
villages and 17000 households; approximately $80 \%$ of adults are subsistence farmers who live on less than US $\$ 1$ per day. ${ }^{20}$ Literacy rates for men and women are $68 \%$ and $49 \%$, respectively. ${ }^{20}$

Our study was nested within a large age and sex representative household survey designed to estimate the prevalence of behavioural risk factors for non-communicable diseases (NCDs). For the parent NCD household survey, ${ }^{21}$ adults $\geq 18$ years were sampled from the health and demographic surveillance site (HDSS) database using stratified sampling techniques. Participants were eligible if they could express themselves in either English or Lusoga (the local language) and had lived at the HDSS for more than 6 months. At the end of the NCD household survey, if participants indicated that they were the parent or caregiver of a child aged 36-59 months, data collectors asked a series of ECDI questions. If there were more than two children aged 36-59 months in the household, responses were only collected for the oldest child. A primary caregiver was defined as an adult who identified as the biological parent or caregiver of the child and had lived with the child for more than 6 months in the selected household.

Written informed consent was obtained from all participants. In cases of illiteracy, consent was administered in the presence of an impartial witness. This study is reported according to the Strengthening the Reporting of Observational Studies in Epidemiology (see online supplemental file).

\section{Patient and public involvement}

Patients or the general public were not involved in the design, or conduct, or reporting or dissemination of the study findings.

\section{Procedure}

The household surveys were conducted from November 2017 to June 2018. A team of trained HDSS staff with experience in household surveys approached sampled participants at their residence. Adults who indicated being the parent/caregiver of a child aged 36-59 months were administered the ECDI questionnaire.
The ECDI questionnaires were completed by participants on the same day. To maintain data fidelity, data collectors received ongoing supervision throughout the study period. Data were collected through face-to-face interviews.

\section{Assessments}

\section{Sociodemographic data}

To understand participants' sociocultural circumstances, sociodemographic data were collected through face-toface interviews. Information asked included age, sex, educational level and marital status. Additionally, questions were asked about their child's age, sex and whether the child was attending school.

\section{Early childhood development}

ECD was assessed using the UNICEF 10-item ECDI. ${ }^{15} 16$ The index has been included in the MICS and in select Demographic and Health Surveys since 2009. ${ }^{15}$ The ECDI was included in the 2016 Demographic and Health Surveys in Uganda. ${ }^{22}$ The ECDI is used to assess ECD in children aged 36-59 across four domains of development: literacy-numeracy, learning/cognition, physical skills and socioemotional development (see table 1). The caregiver is required to provide responses about 10 items, which are then computed into domain and total scores based on the UNICEF ECDI scoring guidelines. ${ }^{6}{ }^{15} \mathrm{~A}$ child is considered to be 'developmentally on track' if the child is found to be on track in at least three of the four domains. ${ }^{12}$ Within each domain, a child is considered to be on track if the caregiver reports that the child can demonstrate at least $50 \%$ of the relevant skills. ${ }^{12}$ For our study, the English version of the ECDI was translated into Lusoga (the local language at the study site) and backtranslated into English by two individuals. Discrepancies were resolved through further discussion by the two translators. The back-translated questionnaire was reviewed by the 25 data collectors in the HDSS and piloted in the community prior to deployment.

Table 1 Developmental domains and skills assessed by the Early Childhood Development Index

\section{Developmental domains}

Literacy-numeracy

Literacy-numeracy

Physical development

Approaches to learning/cognition

Socioemotional development

\section{Questions}

1. Can (name) identify or name at least ten letters of the alphabet?

2. Can (name) read at least four simple, popular words?

3. Does (name) know the name and recognise the symbol of all numbers from 1 to 10 ?

4. Can (name) pick up a small object with two fingers, like a stick or a rock from the ground?

5. Is (name) sometimes too sick to play? (reverse-coded)

6. Does (name) follow simple instructions on how to do something correctly?

7. When given something to do, is (name) able to it independently?

8. Does (name) get along well with other children?

9. Does (name) kick, bite or hit other children or adults? (reverse-coded)

10. Does (name) get distracted easily? (reverse-coded) 


\section{Statistical analysis}

Proportions, means and SD were used to summarise the sociodemographic characteristics of parents/caregivers and their children. Next, to summarise parents' / caregivers' description of a child's developmental skills, items were grouped to create the four domain scores (ie, literacy-numeracy, physical, learning/cognition and social emotional development) based on the ECDI guidelines. ${ }^{12}{ }^{15}$ Frequencies and percentages were used to describe the proportions of children with low development using domain-level data and total scores, in accordance with ECDI guidelines. Children who scored 0 on more than one item in a domain were identified as having low development (or at risk of delay in that domain). ${ }^{9}$ Similarly, children who received a score of 0 on at least three domains were classified as having low overall development status. ${ }^{6}$ The ECDI data were validated using correlational analyses. Specifically, Pearson's correlation analysis was performed to determine the association among the caregiver's educational status, children's age, developmental abilities and children's preschool attendance.

We defined risk profiles based on the dimensions of risk evaluated by the ECDI. Using the ECDI scores in the four domains (ie, literacy-numeracy, learning/cognition, physical skills and socioemotional development), a hierarchical agglomerative cluster analysis (Ward's method) was performed to identify relatively homogenous subgroups of children with similar developmental risk profiles. ${ }^{23} 24$ At the start of this analysis, each individual in its own cluster and each new cluster were formed by merging previous clusters so that within-cluster variation was minimised. ${ }^{23}$ Dendrograms and coefficients in the agglomeration schedule were inspected to determine the optimal number of clusters. The cluster solution that best represents the data was determined by examining the coefficients in the agglomeration schedule, identifying a point where a sizeable change occurs and selecting the number of clusters just before that point. ${ }^{25}$ All analyses were performed using SPSS (V.26.0), with the level of significance established at $\mathrm{p}<0.05$.

\section{RESULTS}

\section{Characteristics of children and caregivers}

In total, caregivers of 720 children ( 360 boys, 360 girls) aged 36-60 months completed the ECDI questionnaire (table 2). Majority of the children $(61.4 \%$ of boys and $56.9 \%$ of girls) did not attend preschool. Majority of the caregivers $(89.2 \%)$ were married and most had not completed secondary school.

\section{Proportion of children with low ECDI scores}

Table 3 summarises the proportion of children with low scores on the four ECDI domains, disaggregated by age and gender. The vast majority of children had low literacynumeracy skills (74.7\%) and a small percentage had poor socioemotional development $(21.8 \%)$. The percentage of those classified as exhibiting low development in the literacy-numeracy domain was higher for boys compared with girls among children $\leq 49$ months. Across all age groups, a greater proportion of boys had low scores in the socioemotional development domain compared with girls (table 3). Only a small fraction of children received

Table 2 Characteristics of children and caregivers

\begin{tabular}{|c|c|c|c|c|c|c|c|c|}
\hline \multicolumn{9}{|c|}{ Sex of child } \\
\hline \multirow[b]{2}{*}{ Variables } & \multicolumn{4}{|c|}{ Male $(n=360)$} & \multicolumn{4}{|c|}{ Female $(n=360)$} \\
\hline & $\begin{array}{l}36-42 \\
\text { months } \\
(n=100)\end{array}$ & $\begin{array}{l}\text { 43-49 months } \\
(n=125)\end{array}$ & $\begin{array}{l}50-56 \text { months } \\
(n=96)\end{array}$ & $\begin{array}{l}57-60 \text { months } \\
(n=39)\end{array}$ & $\begin{array}{l}36-42 \\
\text { months } \\
(n=123)\end{array}$ & $\begin{array}{l}43-49 \\
\text { months } \\
(n=106)\end{array}$ & $\begin{array}{l}50-56 \text { months } \\
(\mathrm{n}=88)\end{array}$ & $\begin{array}{l}57-60 \\
\text { months } \\
(n=43)\end{array}$ \\
\hline \multicolumn{9}{|l|}{ Child characteristics } \\
\hline \multicolumn{9}{|l|}{ Educational status } \\
\hline Attending preschool & $18(18.0)$ & $46(36.8)$ & $47(49.0)$ & $28(71.8)$ & $39(31.7)$ & $46(43.4)$ & $41(46.6)$ & $29(67.4)$ \\
\hline Not attending preschool & $82(82.0)$ & $79(63.2)$ & $49(51.0)$ & $11(28.2)$ & $84(68.3)$ & $60(56.6)$ & $47(53.4)$ & $14(32.6)$ \\
\hline \multicolumn{9}{|l|}{ Caregiver characteristics } \\
\hline Age (years)* & $42(14.1)$ & $44.2(14.3)$ & $43.9(13.3)$ & $41.6(11.6)$ & $41.4(12.8)$ & $44.2(13.8)$ & $43.3(13.3)$ & $45.9(15.9)$ \\
\hline \multicolumn{9}{|l|}{ Sex } \\
\hline Male & $51(51.0)$ & 49 (39.2) & $51(53.1)$ & $15(38.5)$ & $63(51.2)$ & $60(56.6)$ & $38(43.2)$ & $18(41.9)$ \\
\hline Female & $49(49.0)$ & $76(60.8)$ & $45(46.9)$ & $24(61.5)$ & $60(48.8)$ & $46(43.4)$ & $50(56.8)$ & $25(58.1)$ \\
\hline \multicolumn{9}{|l|}{ Educational status } \\
\hline Lower than secondary school & $63(63.0)$ & $89(71.2)$ & $64(66.7)$ & $25(64.1)$ & $81(65.9)$ & $76(71.7)$ & $67(76.1)$ & $30(69.8)$ \\
\hline Secondary school or higher & $37(37.0)$ & $36(28.8)$ & $32(33.3)$ & $14(35.9)$ & $42(34.1)$ & $30(28.3)$ & $21(23.9)$ & $13(30.2)$ \\
\hline \multicolumn{9}{|l|}{ Marital status } \\
\hline Married & $88(88.0)$ & $113(90.4)$ & $82(85.4)$ & $32(82.1)$ & $116(94.3)$ & $99(93.4)$ & $76(86.4)$ & $36(83.7)$ \\
\hline Not married & $12(12.0)$ & $12(9.6)$ & $14(14.6)$ & 7 (17.9) & $7(5.7)$ & $7(6.6)$ & 12 (13.6) & 7 (16.3) \\
\hline
\end{tabular}

Data are $\mathrm{n}(\%)$ unless otherwise indicated.

*Data are mean and SD. 


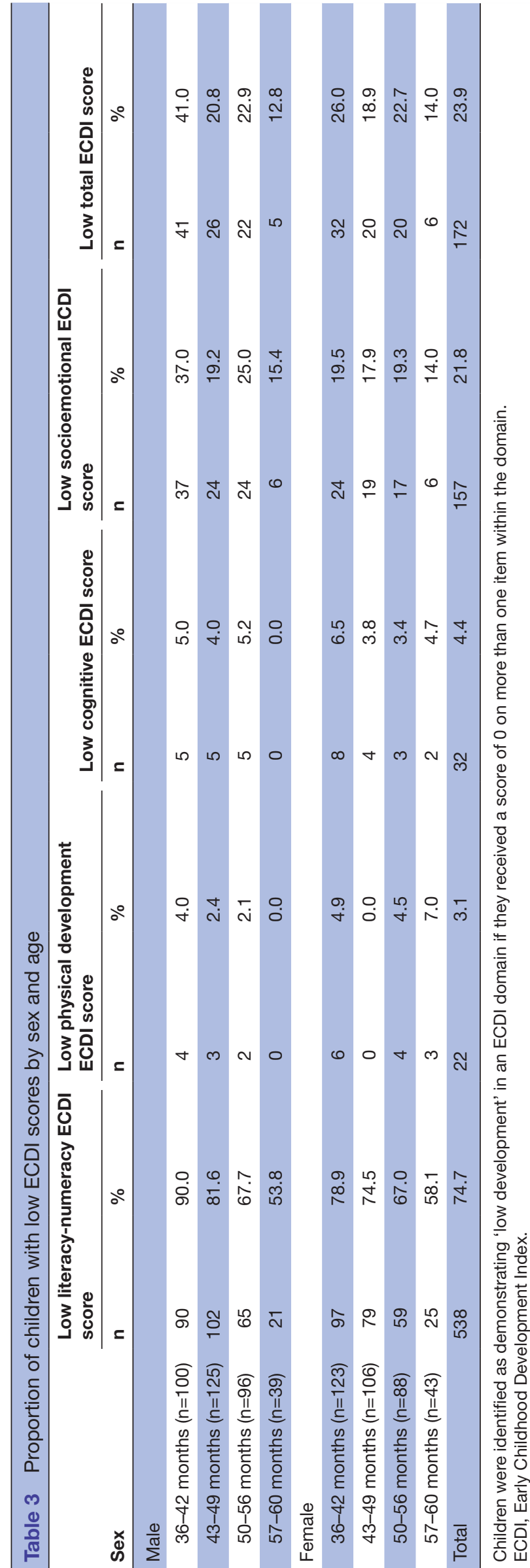

low scores on the physical $(3.1 \%)$ and cognitive $(4.4 \%)$ domains.

\section{Associations among age of child, caregiver's education and ECDI developmental domains}

Table 4 presents the correlations between children's age, caregiver's education and developmental abilities across the four ECDI domains. The analysis revealed that more years of caregiver's education was associated with literacy-numeracy skills $(\mathrm{r}=0.255, \mathrm{p}<0.01)$ and cognitive skills $(\mathrm{r}=0.08, \mathrm{p}<0.05)$. Similarly, advanced literacy skills were positively associated with children's age $(r=0.192$, $\mathrm{p}<0.01)$, cognitive skills $(\mathrm{r}=0.110, \mathrm{p}<0.01)$ and socioemotional development $(r=0.145, \mathrm{p}<0.01)$. Lastly, we found no association between caregiver's education and children's preschool attendance, adjusted for age of child ( $p>0.05)$.

\section{Cluster solution}

Using the criteria described earlier, a three-cluster solution was chosen as best representing the data. The threecluster solution depicting distinct developmental profiles is illustrated in figure 1 and the proportions of children in the clusters are summarised in table 5. The defining characteristics of each cluster are summarised in the next sections. Of note, the ordering of the clusters does not have inherent meaning, but labels are given to each cluster based on the defining characteristics.

\section{Cluster 1: moderate risk}

Cluster 1 comprised 31 children or $4 \%$ of the sample. This group of children had the lowest literacy-numeracy, learning/cognitive and socioemotional scores and were just above the mean on physical skills. About $39 \%$ of the group were children aged between 36 and 42 months.

\section{Cluster 2: low risk, excelling}

Cluster 2 comprised 667 children or $93 \%$ of the sample. This group of children was much higher than the other groups and had scores just above the mean in literacynumeracy, learning/cognitive and physical skills. Indeed, $50 \%$ of this group were boys and $58 \%$ were reported as not attending preschool. Further, $232 \%$ of the reporting caregivers had completed secondary education or higher, whereas less than $10 \%$ of reporting caregivers had completed secondary education or higher in the other two clusters.

\section{Cluster 3: high risk}

Cluster 3 comprised 22 children or $3 \%$ of the sample. This group is characterised by low scores in literacy-numeracy, physical and socioemotional domains, which were all below the mean. Compared with the two other clusters, children in this group had the lowest physical development. Only 7\% of this group were attending preschool (the lowest proportion of any cluster), and therefore the low scores across the measured domains could be attributed to this observation. 
Table 4 Correlations among age of child, parental education and ECDI domains

\begin{tabular}{|c|c|c|c|c|c|c|c|}
\hline Variables & 1 & 2 & 3 & 4 & 5 & 6 & 7 \\
\hline 1. Age of child & - & & & & & & \\
\hline 2. Caregiver's education & -0.045 & - & & & & & \\
\hline 4. Learning/cognition & 0.053 & $0.080^{*}$ & $0.110^{\star *}$ & - & & & \\
\hline 5. Physical skills & 0.017 & 0.009 & 0.066 & 0.001 & - & & \\
\hline 7. ECDI total score & $0.125^{\star *}$ & 0.070 & $0.326^{\star *}$ & $0.369^{\star \star}$ & $0.279^{* \star}$ & $0.777^{\star \star}$ & - \\
\hline
\end{tabular}

${ }^{*} \mathrm{P}<0.05,{ }^{* *} \mathrm{P}<0.01$.

ECDI, Early Childhood Development Index.

\section{DISCUSSION}

We assessed ECD skills and behaviours among a sample of young children living in Iganga and Mayuge districts in eastern Uganda, as reported by their parents/caregivers using the 10-item ECDI developed by UNICEF. Specifically, four questions were addressed: (1) What are the demographic characteristics of parents and children in this sample? (2) What is the percentage of children at risk of delay in each ECDI domain? (3) Is there an association between caregiver's education and children's performance in the developmental domains? (4) Can we identify homogenous groups of children who share similar developmental profiles in this sample?

Caregivers were almost evenly distributed by gender and a vast majority had not completed secondary school education. Majority of the children in this sample were not attending preschool. Overall, approximately $76 \%$ of the children were developing appropriately across the entire index. However, a large proportion of children were at risk of delay in the literacy-numeracy domain $(74.7 \%)$ and a notable proportion were at risk of delay in the socioemotional domain (21.8\%). Boys scored lower than girls on both of these domains. Only a small percentage (less than 5\%) had poor physical and cognitive development. Perhaps, not surprisingly, caregiver's education was positively associated with children's performance on the literacy-numeracy and cognitive skills. However, there was no association between caregiver's education and children's attendance in preschool, adjusted for age of child. Of note, three developmental patterns were identified by cluster analysis, and $\sim 93 \%$ of children could be putatively classified as low risk.

These proportions are alarming on the surface. However, low participation in school likely accounts for the low scores on literacy-numeracy milestones. ${ }^{26}$ Normally, children of educated parents tend to perform

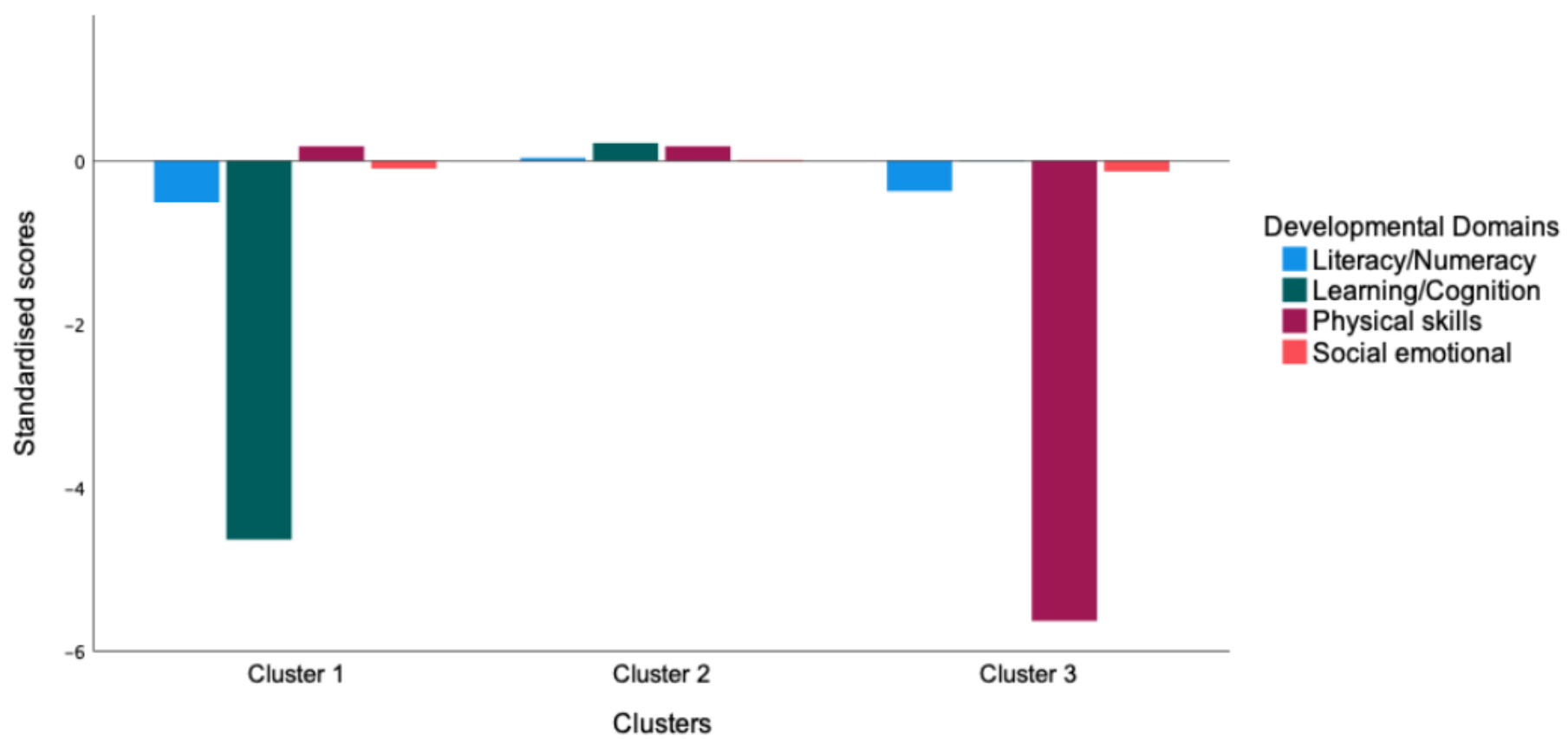

Figure 1 Profile analysis of the three-cluster solution by the features represented as standardised scores in four domains. Sample sizes per cluster are as follows: cluster 1 (putative moderate-risk cluster), $n=31$; cluster 2 (putative low-risk cluster), $\mathrm{n}=667$; cluster 3 (putative high-risk cluster), $\mathrm{n}=22$. 
Table 5 Characteristics of children and caregivers by cluster assignment

\begin{tabular}{|c|c|c|c|}
\hline Variables & $\begin{array}{l}\text { Cluster } 1 \\
(n=31)\end{array}$ & $\begin{array}{l}\text { Cluster } 2 \\
(\mathrm{n}=667)\end{array}$ & $\begin{array}{l}\text { Cluster } 3 \\
(n=22)\end{array}$ \\
\hline \multicolumn{4}{|c|}{ Child characteristics, $\mathrm{n}(\%)$} \\
\hline \multicolumn{4}{|l|}{ Age groups (months) } \\
\hline $36-42$ & $12(38.7)$ & $201(30.1)$ & $10(45.5)$ \\
\hline $43-49$ & $9(29.0)$ & $291(32.8)$ & $3(13.6)$ \\
\hline $50-56$ & $8(25.8)$ & $170(25.5)$ & $6(27.3)$ \\
\hline $57-60$ & $2(6.5)$ & $77(11.5)$ & $3(13.6)$ \\
\hline \multicolumn{4}{|l|}{ Sex } \\
\hline Male & $15(48.4)$ & $336(50.4)$ & $9(40.9)$ \\
\hline Female & $16(51.6)$ & $331(49.6)$ & $13(59.1)$ \\
\hline \multicolumn{4}{|l|}{ Educational status } \\
\hline $\begin{array}{l}\text { Attending } \\
\text { preschool }\end{array}$ & $9(29.0)$ & $278(41.7)$ & $7(31.8)$ \\
\hline $\begin{array}{l}\text { Not attending } \\
\text { preschool }\end{array}$ & $22(71.0)$ & $389(58.3)$ & $15(68.2)$ \\
\hline \multicolumn{4}{|c|}{ Caregiver characteristics, mean (SD) or $\mathrm{n}(\%)$} \\
\hline \multicolumn{4}{|l|}{ Age in years } \\
\hline Mean & 46.9 & 42.9 & 47.9 \\
\hline SD & 13.7 & 13.6 & 15.9 \\
\hline Range & $23-77$ & $18-87$ & $24-78$ \\
\hline \multicolumn{4}{|c|}{ Educational status, n (\%) } \\
\hline $\begin{array}{l}\text { Lower than } \\
\text { secondary school }\end{array}$ & $23(74.2)$ & $455(68.2)$ & 17 (77.3) \\
\hline $\begin{array}{l}\text { Secondary school } \\
\text { or higher }\end{array}$ & $8(25.8)$ & $212(31.8)$ & $5(22.7)$ \\
\hline \multicolumn{4}{|l|}{ Marital status, n (\%) } \\
\hline Married & $30(96.8)$ & $595(89.2)$ & $17(77.3)$ \\
\hline Never married & $1(3.2)$ & $72(10.8)$ & $5(22.7)$ \\
\hline
\end{tabular}

better on literacy-numeracy tasks compared with peers of uneducated parents. ${ }^{27}$ Unlike high-income countries, children aged 3-4 years old in some rural Uganda communities rarely attend any form of organised learning activity unless sent to day care, which is usually done by few higher-income families where both the mother and the father work outside the home. Thus, only a small proportion of children in this age bracket get the opportunity to develop literacy-numeracy skills. Furthermore, research has suggested that home environment characterised by joint book reading between the parents and the child positively affects children's literacy-numeracy development. ${ }^{27}$ However, the lack of such environments in most rural households in Uganda might explain the high proportion of children with low literacy skills in this sample. In addition, the questionable nature of the items in this particular domain could explain the low scores received by the children. Limitations of the ECDI literacy-numeracy items have been previously acknowledged. ${ }^{6}$ McCoy et al ${ }^{6}$ have indicated that these items represent measures of academic knowledge rather than general developmental competence and may be too difficult for young children.
It is therefore not surprising that the 3-year-olds in our sample received lower scores as compared with their 4-year-old peers. Additional research is needed to develop age-appropriate and culturally appropriate early literacynumeracy measure to improve ECD assessments in these settings. Another plausible explanation may relate to the nature of African traditional education. ${ }^{28}$ In typical traditional African settings, early childhood education does not focus solely on literacy and numeracy skills, but rather infants and toddlers are taught to learn the cultural practices and behaviours as well as acceptable social standards and conventions. ${ }^{28} 29$ Thus, adults in many rural Africans settings tend to place more value on the development of good character and socially acceptable behaviour than on Western-based academic knowledge and skills. ${ }^{30}$

McCoy et at ${ }^{6}$ estimated that more than one-third of children in LMICs have poor ECDI scores in cognitive and/or socioemotional domains. In the current study, we found that $22 \%$ of children aged 3 and 4 years old in rural Uganda had low socioemotional development and less than $5 \%$ of children showed poor cognitive development. Clearly, our estimates of the proportion of children who are not developmentally on track in socioemotional and cognitive domains are lower than what was reported by McCoy and colleagues. ${ }^{6}$ These observations may be explained by several important factors, such as differences in sample size, participant selection and population characteristics. Even though McCoy et at used ECDI data, they analysed pooled data from 99222 children living in 35 LMICs. Further, their data were obtained from a nationally representative sample in all the countries included. However, the present study is based on data derived from one HDSS in Uganda and involved a community sample of 720 children and caregivers. It should be noted that our results appear to corroborate what was reported in the 2016 Uganda Demographic and Health Survey indicators. ${ }^{22}$ While most children demonstrated high scores in areas such as physical and cognitive development, about three-fourths of children were reported to have poor literacy-numeracy skills and almost a quarter demonstrated low socioemotional skills. Our finding that caregiver's education was positively associated with children's cognitive and literacy skills supports previous work which demonstrated that higher parental educational level influences developmental outcomes. ${ }^{31}$ This result provides some form of validation to support the utility of the ECDI in the study setting.

The cluster analysis revealed a high-risk subgroup that comprised $3 \%$ of the sample. This proportion approximately corresponds to upper bounds of Western estimates for developmental delays in this age range. ${ }^{26}$ While this group was lower than average in the literacy, physical and socioemotional development domains, the key distinguishing factor was the physical domain. Perhaps, the children in this group had fewer opportunities to engage in motor activities or interact with people and objects to build their physical skills. This may partly be due to limited access to organised physical activity or 
preschool as evidenced by the small percentage of children attending school in this cluster. While speculative, this high-risk group may be defined by delayed executive function development. But to reiterate, a very small proportion of these children were enrolled in preschool, a context that can often facilitate the development of these developmental skills. Further, $4 \%$ of children were found to have moderate risk for low development. These children are the ones that can easily slip into high-risk status if they are not given appropriate attention. These statistics indicate that about $5 \%$ of rural Ugandan children may be at risk of not reaching their developmental potential, particularly in the areas of literacy-numeracy and cognitive skills. These data can support targeted policy interventions and programmes to address the developmental challenges identified in these subgroups. Early childhood educators, practitioners and policy makers should be concerned about the 'at risk' subgroups and identify appropriate strategies to improve their developmental ability in specified domains to prepare them for future academic or work life. The need to improve or extend service coverage to rural children is great, as is the need for more culturally appropriate assessment practices and interventions.

In many African countries, the nature by which infants and young children interact with their environment also varies in comparison with Western cultures. ${ }^{28}$ Aspects of the early social environment that augment executive function in Western cultures may be different in Uganda. More work is needed to elucidate whether this cognitive 'risk' actually represents cognitive delays, as well as moderating and mediating factors in this context. That said, there may be culturally normative aspects of the proximal environment that sufficiently foster executive function development, as $84 \%$ of the sample were reported to possess key cognitive skills that align with executive functioning.

Our study has several important strengths. The crosssectional design allowed us to recruit a relatively large sample and avoids the potential biases of repeated questioning and undue respondent fatigue. Second, we included a relatively large population-representative sample recruited from rural communities in Uganda. The ECDI provides global estimates of ECD from four developmental domains, making it easier to assess multiple domains over a short period of time. The ECDI data are important for informing national strategies in terms of interventions and policies. Despite these strengths, the study also has some limitations. We did not include a nationally representative sample as was done in previous MICS studies due to logistical constraints. Importantly, the ECDI has not been formally validated in Uganda and some of the items have questionable validity. Another limitation is the lack of precision in estimating children's developmental ability with a few items (1-3 items) per domain over a 2-year age range. The ECDI was designed for a wide age range (36-59 months). Given the dynamic nature of development, this wide age bracket makes it difficult to determine whether high ECDI scores reflect one's developmental skills or normal growth and maturation. More work is needed on the MICS-ECDI in Uganda to confirm the psychometric properties of this tool in different cultural contexts.

Despite these limitations, our study has demonstrated that the majority of children had poor literacy-numeracy skills. The study confirmed that the low proportion of children attending preschool in rural Uganda is reflected by low proportion of children meeting literacy-numeracy milestones. Beyond this observation, we identified a subgroup of children aged 3 and 4 years old who were disproportionately at risk of cognitive delays, a group that warrants follow-up assessment by trained behavioural health service providers. This work contributes to a foundation for ongoing work continuing to develop ECD screening, assessment and intervention infrastructure in Uganda and other LMICs in Sub-Saharan Africa.

\section{Author affiliations}

${ }^{1}$ The Elison Lab for Developmental Brain and Behaviour Research, University of Minnesota Twin Cities, Minneapolis, Minnesota, USA

${ }^{2}$ Department of Psychiatry, Makerere University, CHS, Kampala, Uganda ${ }^{3}$ Institute of Child Development, University of Minnesota Twin Cities, Minneapolis, Minnesota, USA

${ }^{4}$ Department of Paediatrics, University of Utah Health, Salt Lake City, Utah, USA ${ }^{5}$ Department of Epidemiology, Johns Hopkins University, Baltimore, Maryland, USA ${ }^{6}$ Department of Disease Control and Environmental Health, Makerere University CHS, Kampala, Uganda

${ }^{7}$ International Health, Johns Hopkins University Bloomberg School of Public Health, Baltimore, Maryland, USA

${ }^{8}$ Centre for Health and Population Research (MUCHAP), Makerere University, Kampala, Uganda

${ }^{9}$ Department of Health Policy, Planning and Management, School of Public Health, Makerere University, Kampala, Uganda

${ }^{10}$ Centre for Tobacco Control in Africa, Makerere University, Kampala, Uganda

${ }^{11}$ Milken Institute of Public Health, George Washington University, Washington, District of Columbia, USA

\section{Twitter Dan Kajungu @dkaj04}

Acknowledgements We are in debt to the efforts of research assistants working at the Health and Demographic Surveillance Site in Iganga-Mayuge in Uganda and the respondents for their participation.

Contributors DG and AW conceived the study. DG, CS, ER, DK, GP and AAH implemented the study and provided study supervision. DG, EB, MV, SS and JE analysed and interpreted the data. EB wrote the first draft of the manuscript, which was critically revised by all authors. All authors reviewed and approved the final manuscript.

Funding This work was made possible by a grant from the National Institutes of Health (NIH) (R21 TW010415) to DG and AAH. Research reported in this publication was also supported by the Fogarty International Center (FIC) of the NIH under grant number D43TW009345 awarded to the Northern Pacific Global Health Fellows

Program. The content is solely the responsibility of the authors and does not necessarily represent the official views of the NIH. The funders had no role in study design, data collection, analysis, data interpretation or the writing of the report.

\section{Competing interests None declared.}

Patient consent for publication Not required.

Ethics approval Ethical approval was obtained from the Makerere University School of Public Health (MakSPH) Higher Degrees and Research and Ethics Committee (HDREC-526), Uganda, and the Uganda National Council for Science and Technology (SS-4477). The Johns Hopkins Bloomberg School of Public Health Institutional Review Board (JHSPH IRB) deferred ethical oversight to MakSPH's HDREC.

Provenance and peer review Not commissioned; externally peer reviewed. 
Data availability statement No additional data available.

Supplemental material This content has been supplied by the author(s). It has not been vetted by BMJ Publishing Group Limited (BMJ) and may not have been peer-reviewed. Any opinions or recommendations discussed are solely those of the author(s) and are not endorsed by BMJ. BMJ disclaims all liability and responsibility arising from any reliance placed on the content. Where the content includes any translated material, BMJ does not warrant the accuracy and reliability of the translations (including but not limited to local regulations, clinical guidelines, terminology, drug names and drug dosages), and is not responsible for any error and/or omissions arising from translation and adaptation or otherwise.

Open access This is an open access article distributed in accordance with the Creative Commons Attribution Non Commercial (CC BY-NC 4.0) license, which permits others to distribute, remix, adapt, build upon this work non-commercially, and license their derivative works on different terms, provided the original work is properly cited, appropriate credit is given, any changes made indicated, and the use is non-commercial. See: http://creativecommons.org/licenses/by-nc/4.0/.

\section{ORCID iDs}

Emmanuel Bonney http://orcid.org/0000-0001-7179-2816

Elizeus Rutebemberwa http://orcid.org/0000-0001-8363-7928

\section{REFERENCES}

1 Lu C, Cuartas J, Fink G, et al. Inequalities in early childhood care and development in low/middle-income countries: 2010-2018. BMJ Glob Health 2020;5:e002314.

2 Shonkoff JP, Richter L, van der Gaag J, et al. An integrated scientific framework for child survival and early childhood development. Pediatrics 2012;129:e460-72.

3 Black MM, Walker SP, Fernald LCH, et al. Early childhood development coming of age: science through the life course. Lancet 2017;389:77-90.

4 Ertem IO, Krishnamurthy V, Mulaudzi MC, et al. Similarities and differences in child development from birth to age 3 years by sex and across four countries: a cross-sectional, observational study. Lancet Glob Health 2018;6:e279-91.

5 Richter LM, Daelmans B, Lombardi J, et al. Investing in the foundation of sustainable development: pathways to scale up for early childhood development. Lancet 2017;389:103-18.

6 McCoy DC, Peet ED, Ezzati M, et al. Early childhood developmental status in low- and middle-income countries: national, regional, and global prevalence estimates using predictive modeling. PLoS Med 2016;13:e1002034.

7 Gladstone M, Lancaster GA, Umar E, et al. The Malawi developmental assessment tool (MDAT): the creation, validation, and reliability of a tool to assess child development in rural African settings. PLOS Med 2010;7:e1000273.

8 Gladstone M, Lancaster G, Umar E, et al. Perspectives of normal child development in rural Malawi - a qualitative analysis to create a more culturally appropriate developmental assessment tool. Child Care Health Dev 2010;36:346-53.

9 Gladstone MJ, Lancaster GA, Jones AP, et al. Can Western developmental screening tools be modified for use in a rural Malawian setting? Arch Dis Child 2008;93:23-9.

10 Sabanathan S, Wills B, Gladstone M. Child development assessment tools in low-income and middle-income countries: how can we use them more appropriately? Arch Dis Child 2015;100:482-8.
11 Richter L, Black M, Britto P, et al. Early childhood development: an imperative for action and measurement at scale. BMJ Glob Health 2019;4:e001302.

12 Lu C, Cuartas J, Fink G, et al. Inequalities in early childhood care and development in low/middle-income countries: 2010-2018. BMJ Global Health 2020;5:e002314.

13 Lansdown RG, Goldstein H, Shah PM, et al. Culturally appropriate measures for monitoring child development at family and community level: a who Collaborative study. Bull World Health Organ 1996;74:283.

14 Bornstein MH, Britto PR, Nonoyama-Tarumi Y, et al. Child development in developing countries: introduction and methods. Child Dev 2012;83:16-31.

15 Loizillon A, Petrowski N, Britto P, et al. Development of the early childhood development index in MICs surveys. MICs methodological papers, no. 6, data and analytics section, division of data, research and policy. New York, NY, USA: UNICEF, 2017.

16 Khan S, Hancioglu A. Multiple indicator cluster surveys: delivering robust data on children and women across the globe. Stud Fam Plann 2019;50:279-86.

17 Okungu V, Mweu M, Mans J, Sustainability MJ, et al. Sustainability, equity and effectiveness in public financing for health in Uganda: an assessment of maternal and child health services. International Journal of Health Services Research and Policy 2019;4:233-46.

18 Sensalire S, Isabirye P, Karamagi E, et al. Saving mothers, giving life approach for strengthening health systems to reduce maternal and newborn deaths in 7 scale-up districts in northern Uganda. Global Health: Science and Practice, 2019: 7(Supplement 1). S168-87.

19 National Integrated Early Childhood Development Policy of Uganda [Internet]. Available: https://health.go.ug/content/national-integratedearly-childhood-development-policy-uganda [Accessed cited 9 Jan 2020].

20 Waiswa P, Peterson S, Tomson G, et al. Poor newborn care practices - a population based survey in eastern Uganda. BMC Pregnancy Childbirth 2010;10:9.

21 Kajungu D, Hirose A, Rutebemberwa E, et al. Cohort profile: the Iganga-Mayuge health and demographic surveillance site, Uganda (IMHDSS, Uganda). Int J Epidemiol 2020;49:1082-1082g.

22 Uganda Bureau of Statistics (UBOS) and ICF. Uganda demographic and health survey 2016. Kampala, Uganda and Rockville, Maryland, USA: UBOS and ICF, 2018.

23 Aldenderfer MS, Blashfield RK. Cluster analysis. Newberry Park, 1984.

24 Milligan GW, Cooper MC. Methodology review: clustering methods. Appl Psychol Meas 1987;11:329-54.

25 Green JA. Analyzing individual differences in development: correlations and cluster analysis. individual differences in infancy: reliability, stability, prediction 1990:77-109.

26 Rosenberg SA, Zhang D, Robinson CC. Prevalence of developmental delays and participation in early intervention services for young children. Pediatrics 2008;121:e1503-9.

27 Bennett KK, Weigel DJ, Martin SS. Children's acquisition of early literacy skills: examining family contributions. Early Child Res $Q$ 2002;17:pp.:295-317.

28 Adeyemi MB. Some key issues in African traditional education. McGill Journal of Education 2002;37:223-40.

29 Adeyemi MB, Adeyinka AA. The principles and content of African traditional education. Educational Philosophy and Theory 2003;35:425-40.

30 Super CM, Harkness S, Barry O, et al. Think locally, act globally: contributions of African research to child development. Child Dev Perspect 2011;5:119-25.

31 Dickson M, Gregg P, Robinson H, Early RH. Early, late or never? when does parental education impact child outcomes? The Economic Journal 2016;126:F184-231. 